\title{
An Embryonated Egg Transmission Model for Epizootic Hemorrhagic Disease Virus
}

\author{
Kishana Y. Taylor, ${ }^{\star}$ Mark G. Ruder, Daniel G. Mead, and David E. Stallknecht
}

\begin{abstract}
Epizootic hemorrhagic disease virus (EHDV) is a vector-borne orbivirus of ruminants; in North America there are three serotypes (EHDV-1, -2, and -6) and these primarily affect white-tailed deer (Odocoilus virginianus). EHDV is vectored by biting midges, Culicoides spp. Embryonated chicken eggs (ECE) have recently been used as an experimental host to investigate the vector competence of Australian Culicoides spp. for bluetongue serotype virus 1 and 23. In this study, we evaluated the use of the ECE model to determine its applicability for evaluating vector competence related to transmission of North American EHDV serotypes. We demonstrated that all three North American EHDV serotypes were able to replicate in ECEs and be transmitted from infected ECEs to Culicoides sonorensis Wirth \& Jones. In addition, we were able to complete the transmission cycle from infected C. sonorensis to uninfected ECEs for EHDV-1 and -2.
\end{abstract}

Keywords: EHDV, Culicoides, virus transmission

\section{Introduction}

$C$ UliCoides (Diptera: Ceratopogonidae) are hematophagous biting insects that transmit several viral pathogens important to human and/or animal health, including Oropouche virus (OPV), Schmallenburg virus (SBV), bluetongue virus (BTV) and epizootic hemorrhagic disease virus (EHDV). In North America, EHDV (genus Orbivirus, family Reoviridae) causes orbiviral hemorrhagic disease in wild ruminants, especially white-tailed deer (WTD; Odocoileus virginianus) and has recently been associated with increasing disease in domestic ruminants (Ruder et al. 2015a). There are three serotypes of EHDV endemic to North America (EHDV-1, -2 , and -6), and all of them can cause severe disease in WTD (Savini et al. 2011, Ruder et al. 2015a).

In North America, only one species, Culicoides sonorensis Wirth \& Jones, formerly known as Culicoides variipennis, is a confirmed vector of EHDV (Foster et al. 1977). However, it is suspected that other Culicoides species may also be involved in transmission (Ruder et al. 2015a, McGregor et al. 2019). For example, Culicoides debilipalpis Lutz, formerly known as $C$., and Culicoides stellifer Coquillett have been suggested as potential vectors due to spatial-temporal association with WTD during EHD outbreaks (Ruder et al. 2015a, McGregor et al. 2019). Natural hosts for EHDVs are restricted to certain species of domestic and wild ruminants, and there are no laboratory animal models in which transmission has been efficiently demonstrated. For this reason, WTD have often been used in North American EHDV transmission studies (Smith and Stallknecht 1996, Ruder et al. 2012, 2015a). There is a need for a laboratory animal infection model that can facilitate vector incrimination studies.

Embryonated chicken eggs (ECEs) provide a costeffective and labor-efficient way to investigate the vector competence of Culicoides spp.; they have been used to infect both field-collected and laboratory-reared Culicoides with various BTV serotypes (Foster and Jones 1973, Van Der Saag et al. 2017). The primary goal of this research was to evaluate the ECE transmission model for North American EHDV.

\section{Methods}

Single passages of EHDV-1, EHDV-2, and EHDV-6 from the spleens of WTD (first isolated on cattle pulmonary artery endothelial cells [CPAEs]) were propagated from stock on baby hamster kidney $\left(\mathrm{BHK}_{21}\right.$; American Type Culture Collection) cells and prepared as previously described (Ruder et al. 2015b). Specific pathogen-free 11-day-old ECEs (Poultry Research Diagnostic Center, UGA, Athens, GA) were obtained in batches $(n=36$ or $n=72)$ and candled to ensure viability and visualize the extraembryonic blood vessels. A hole was made in the egg shell over a selected

Southeastern Cooperative Wildlife Disease Study, College of Veterinary Medicine, University of Georgia, Athens, Georgia, USA.

*Current affiliation: Microbiology and Molecular Genetics, University of California, Davis, Davis, California, USA. 
blood vessel and ECEs were intravenously inoculated with $\sim 50 \mu \mathrm{L}$ of $10^{5} \mathrm{TCID}_{50} / \mathrm{mL}$ or higher of EHDV-1 $(n=156)$, EHDV-2 $(n=144)$, or EHDV-6 $(n=48)$ with a 30 -gauge needle. Eggs with large amounts of blood loss were discarded. The inoculation site was then sealed using Elmer's glue (Columbus, Ohio). ECEs were incubated for $45-48 \mathrm{~h}$ at $37.8^{\circ} \mathrm{C}$.

Pupae were shipped overnight from the Arthropod-Borne Animal Disease Research Unit (USDA USDA, Manhattan, KS, USA) and emerged during shipment. Midges were held for an additional 24-48 $\mathrm{h}$ to allow mouthparts to harden before feeding. Midges were fed according to the methods described by Van der Saag et al. (2017), with a reduced feeding period of $2-3 \mathrm{~h}$. In brief, the top of the eggshell above the air cell was removed and a modified $50 \mathrm{~mL}$ conical tube feeding cage was taped to the top of the egg. Mixed sex Culicoides midges were placed into the tube, allowed to feed for $2-3 \mathrm{~h}$ in a dark incubator at $33^{\circ} \mathrm{C}$, and then removed. Visibly blood-engorged females were immobilized with carbon dioxide $\left(\mathrm{CO}_{2}\right)$, separated and then incubated at $25^{\circ} \mathrm{C}$ in the dark for 9-10 days with cotton balls soaked in a $10 \%$ glucose solution as their primary food source.

After the extrinsic incubation period, any surviving females were placed into a feeding chamber attached to fresh uninoculated 11-day-old (receiver) and given the opportunity to take a bloodmeal for $2 \mathrm{~h}$ under previously mentioned feeding conditions. After the 2 -h feeding period, midges were anesthetized with $\mathrm{CO}_{2}$ and individually placed into $1.5 \mathrm{~mL}$ micro-centrifuge tubes with $600 \mu \mathrm{L}$ of Minimum Essential Media with $4 \times$ antibiotics/antimycotics (100 U, penicillin; $0.1 \mathrm{mg}$, streptomycin; $0.25 \mathrm{mg} / \mathrm{mL}$, amphotericin B; Sigma). The midges were homogenized for subsequent titration and supernatants were inoculated on to $\mathrm{BHK}_{21}$ cells as described in Ruder et al. (2012). In brief, midges were homogenized with mini-pestles and centrifuged at $1200 \times g$ for $5 \mathrm{~min}$. Two hundred microliters of supernatant was inoculated onto BHK cells and incubated at $34^{\circ} \mathrm{C}$. Cells were monitored for CPE for 7 days, then passaged onto fresh BHK cells and monitored for an additional 7 days. Isolated virus was identified by serum neutralization assays and titrated out to a dilution of 1:1000.

Postfeeding, donor embryos were removed from the egg, decapitated, placed in $10 \mathrm{~mL}$ of MEM, homogenized, and then sonicated. Homogenized embryos were then centrifuged at $1200 \times g$ for $10 \mathrm{~min}$. Supernatant from each sample
$(100 \mu \mathrm{L})$ was titrated (median tissue culture infective doses, $\mathrm{TCID}_{50}$ ) on CPAE cells in a 96-well plate format. Postfeeding, receiver ECEs were incubated at $37.8^{\circ} \mathrm{C}$ and checked daily for 4 days for death and titrated as described earlier. Each inoculated egg that resulted in an infected midge was considered successful transmission event.

When possible, due to dead embryos, blood was collected from receiver ECEs by severing the exposed extraembryonic blood vessel from the top of the egg where the shell had been removed for feeding. Blood was collected using a $200 \mu \mathrm{L}$ micropipette. Red blood cells $(10 \mu \mathrm{L})$ were lysed by diluting $1: 10$ in sterile water and sonicating and then titrated as previously described (Ruder et al. 2012).

\section{Results}

A total of $751 C$. sonorensis $(n=322$, EHDV $-1, n=359$, EHDV-2, $n=70$, EHDV-6) fed on infected ECEs $(n=5$, EHDV-1, $n=751$, EHDV-4, $n=1$, EHDV-6). Successful $\mathrm{Cu}$ licoides feeding rates, as determined by visibly bloodengorged females, varied from $32.7 \%$ to $68.6 \%$ (Table 1). Survivorship during the extrinsic incubation period was low (5.8-48.6\%). Seventeen midges that fed on receiver eggs were determined to be positive for EHDV by virus isolation and titration. Two midges ( $n=1, \mathrm{EHDV}-2$ and $n=1, \mathrm{EHDV}-1)$ had titers $>10^{2.7}$ TCID $_{50} /$ midge. The remaining midges $(n=15)$ had titers $<10^{2.7}$ TCID $_{50} /$ midge, which could be a potential cutoff value for vector competency (Ruder et al. 2012).

The successful transfer of virus from infected egg to naive midges occurred with all the viruses that were used (Table 1). The viruses were acquired from donor ECEs to midges upon feeding in five events for EHDV-1, four separate feeding trials for EHDV-2, and a single event for EHDV-6. Blood was collected and titered from four of the receiver ECEs ( $n=2, \mathrm{EHDV}-2$, and $n=2, \mathrm{EHDV}-1$ ) (Table 1). The average blood titers of receiver ECEs were $10^{5.1} \mathrm{TCID}_{50} / \mathrm{mL}$ for EHDV-1 and $10^{3.45}$ TCID $_{50} / \mathrm{mL}$ for EHDV -2 .

Successful virus transfer from infected midges to naive recipient ECEs was detected for EHDV-1 and -2. In some virus-positive recipient ECEs $(n=5)$, the embryos died by day 3 postmidge feeding. These embryos often displayed extensive hemorrhaging in the head and neck.

Table 1. Summary of Successful Transmission Events to AND From Culicoides SONORENSIS Biting Midges of Epizootic Hemorrhagic Disease Virus by Strain

\begin{tabular}{|c|c|c|c|c|c|c|c|}
\hline $\begin{array}{l}\text { EHDV } \\
\text { serotype }\end{array}$ & $\begin{array}{c}\text { Donor ECE } \\
\text { virus titer, } \\
10 \times \text { TCID }_{50} / \mathrm{mL}\end{array}$ & $\begin{array}{c}\text { Midges placed } \\
\text { on ECEs (no. } \\
\text { of engorged) }\end{array}$ & $\begin{array}{l}\text { Extrinsic, } \\
\text { incubation } \\
\text { period, days }\end{array}$ & $\begin{array}{c}\text { Incubation } \\
\text { temperature } \\
\left({ }^{\circ} \mathrm{C}\right)\end{array}$ & $\begin{array}{l}\text { Midges } \\
\text { survived } \\
\quad(\%)\end{array}$ & $\begin{array}{l}\text { Infected } \\
\text { midges, } \\
\mathrm{n}(\%)\end{array}$ & $\begin{array}{l}\text { Receiver ECE } \\
\text { virus titer, } \\
10 \times T C I D_{50} / \mathrm{mL}\end{array}$ \\
\hline 1 & 5.1 & 77 (37) & 10 & 25 & $18(48.6)$ & $1(5.5)$ & 4.1 \\
\hline 1 & 4.1 & $125(67)$ & 10 & 25 & 7 (10.4) & $1(14.2)$ & 3.1 \\
\hline 1 & 2.9 & $153(88)$ & 9 & 25 & $21(23.8)$ & 3 (14.2) & 3.1 \\
\hline 1 & 5.1 & $94(62)$ & 9 & 25 & $20(32.2)$ & $1(5)$ & 5.1 \\
\hline 1 & 2.1 & 99 (68) & 9 & 25 & $4(5.8)$ & $1(25)$ & 2.17 \\
\hline 2 & 3.1 & 300 (159) & 10 & 25 & $10(6.2)$ & $3(30)$ & ND \\
\hline 2 & 3.1 & 177 (115) & 10 & 25 & $9(7.8)$ & $2(22.2)$ & 5.1 \\
\hline 2 & 2.3 & $74(45)$ & 9 & 25 & $22(48.8)$ & $1(4.5)$ & 4.1 \\
\hline 2 & 2.6 & $122(40)$ & 9 & 25 & $22(55)$ & $3(13.6)$ & 5.1 \\
\hline 6 & 5.1 & $164(70)$ & 10 & 25 & $14(20)$ & $1(7.1)$ & ND \\
\hline
\end{tabular}

Each row represents a successful transmission event from infected egg to naive midge or infected egg to naive midge and infected midge to naive egg.

ECE, embryonated chicken egg; EHDV, epizootic hemorrhagic disease virus; ND, not detected. 


\section{Discussion}

This study demonstrated that all of the North American EHDV serotypes could be transmitted from an infected ECE to noninfected midges. However, no EHDV-6infected midges were able to infect receiver ECEs. A possible explanation for this result could be there was low survivorship of EHDV-6 infected midges or that if a larger number of EHDV-6 infected ECEs were tested a transmission event would occur. An alternative explanation could be that $C$. sonorensis is not a completely competent vector for EHDV-6. Prior studies (Ruder et al. 2015b) have demonstrated low EHDV-6 infection rates of colonized C. sonorensis. In addition, Tabachnick (1991) reported that C. sonorensis' susceptibility to different serotypes and strains of BTV varied; a similar pattern may exist for different EHDV serotypes. Further testing is necessary to eliminate the possibility that better survivorship or larger sample size can account for the difference in midge to edge EHDV-6 transmission.

This model represents a promising tool to investigate vector competence for a number of Culicoides species that are suspected to play a role in EHDV transmission in the United States. Future studies are necessary to test this model with field-collected Culicoides spp., specifically $C$. debilipalpis and $C$. stellifer, which have been identified as potential EHDV vectors (Smith and Stallknecht 1996, Ruder et al. 2015a).

\section{Acknowledgments}

The authors thank Jim Kempert and William Yarnell (ABADRU, USDA) for providing midges and Elmer Gray (Department of Entomology, UGA) for the use of his facilities during this study. The authors appreciate the continued support of Southeastern Cooperative Wildlife Disease Study (SCWDS) member agencies.

\section{Author Disclosure Statement}

No competing financial interests exist.

\section{Funding Information}

No funding was received for this article.

\section{References}

Foster NM, Breckon RD, Ludke AJ, Jones RH, et al. Transmission of two strains of epizootic hemorrhagic disease virus in deer by Culicoides variipennis. J Wildl Dis 1977; 1:9-16.

Foster N, Jones R. Bluetongue virus transmission with Culicoides variipennis via embryonating chicken eggs. J Med Entomol 1973; 10:529-532.

McGregor BL, Sloyer KE, Sayler KA, Goodfriend O, et al. Field data implicating Culicoides stellifer and Culicoides venustus (Diptera: Ceratopogonidae) as vectors of epizooting hemorrhagic disease virus. Parasit Vectors 2019; 12:258-271.

Ruder MG, Howerth EW, Stallknecht DE, Allison AB, et al. Vector competence of Culicoides sonorensis (Diptera: Ceratopogonidae) to epizootic hemorrhagic disease virus serotype 7. Parasit Vectors 2012; 5:236-244.

Ruder MG, Lysyk TJ, Stallknecht DE, Foil LD, et al. Transmission and epidemiology of bluetongue and epizootic hemorrhagic disease in North America: Current perspectives, research gaps, and future directions. Vector Borne Zoonotic Dis 2015a; 15:348-363.

Ruder MG, Stallknecht DE, Allison AB, Mead DG, et al. Host and potential vector susceptibility to an emerging orbivirus in the United States: Epizootic hemorrhagic disease virus serotype 6. Vet Pathol 2015b; 53:574-584.

Savini G, Afonso A, Mellor P, Aradaib I, et al. Epizootic hemorrhagic disease. Res Vet Sci 2011; 91:1-17.

Smith KE, Stallknecht DE. Culicoides (Diptera: Ceratopogonidae) collected during epizootics of hemorrhagic disease among captive white-tailed deer. J Med Entomol 1996; 33:507-510.

Tabachnick W. Genetic control of oral susceptibility to infection of Culicoides variipennis with bluetongue virus. Am J Trop Med Hyg 1991; 45:666-671.

Van Der Saag MR, Ward MP, Kirkland PD. Application of an embryonated chicken egg model to assess the vector competence of Australian Culicoides midges for bluetongue viruses. Med Vet Entomol 2017; 31:263-271.

Address correspondence to: Kishana Y. Taylor Microbiology and Molecular Genetics University of California, Davis Shields Avenue, Briggs Hall, Room 255 Davis, CA 95616-5270

USA

E-mail: kyvtaylor@ucdavis.edu 